\title{
THE EFFECT ON VIRULENCE OF TRANSFERRING R FACTORS TO SALMONELLA TYPHIMURIUM IN VIVO
}

\author{
H. Williams SMith
}

\author{
Houghton Poultry Research Station, Houghton, Huntingdon
}

Watanabe AND Watanabe (1969) reported that the mouse-virulence of smooth $\mathrm{R}$ factor-containing $\left(\mathrm{R}^{+}\right)$strains of Salmonella typhimurium was usually lower than those of their fully antibiotic-sensitive $\left(\mathrm{R}^{-}\right)$parent strain. When the experiments were later repeated (Watanabe, 1971), this difference disappeared and the irreproducibility of the earlier results was attributed to the genetic heterogenicity of the mice used for assessing virulence. In similar experiments, Thiele (1970) observed that some smooth $\mathrm{R}^{+}$strains of $S$. typhimurium were avirulent, whereas others possessed the same degree of virulence as their $\mathbf{R}$ parent strain.

The $\mathrm{R}^{+}$strains studied by Watanabe and Watanabe, and by Thiele, had been obtained by mixed cultivation of $\mathrm{R}^{-}$strains of $S$. typhimurium and $\mathrm{R}^{+}$ strains of Escherichia coli. Their virulence was assessed by the intraperitoneal injection of mice. To obtain further information on the subject, it was decided to compare the virulence of strains of $S$. typhimurium to which $\mathrm{R}$ factor had been transferred experimentally in the alimentary tract since this resembles more closely the manner in which they are acquired under natural conditions.

Two antibiotic-sensitive parent strains of $S$. typhimurium were used in these studies, chosen because $\mathrm{R}$ factors could be transferred to them fairly easily in vivo (Smith, 1970). Virulence was assessed in 1-day-old male chicks because they were available in large numbers, thus permitting the detection of minor differences between bacterial strains. The chicks were infected orally rather than parentally because the oral route is the natural route of salmonella infection.

\section{MATERIALS AND METHODS}

The preparation of $R^{+}$strains of Salmonella typhimurium in vivo. The method previously described was used (Smith, 1970). For the first 3 days of life, chicks, from salmonella-free parent stock, were given drinking-water to which suspensions of non-pathogenic strains of Escherichia coli containing different $\mathbf{R}$ factors had been added. On the 4th day, the contaminated drinking water was replaced by clean water and the chicks were given, by mouth, approximately $10^{9}$ viable organisms of antibiotic-sensitive Salmonella typhimurium strain 5235 (phage type 29) or strain 98 (phage type 14) or nalidixic-acid-resistant (nal ${ }^{r}$ ) mutants of these strains. Strain 5235 had been received from Dr E. S. Anderson of the Enteric Reference Laboratory, London, NW9 5HT. Neither strain 5235 nor strain 98 had been found to possess transfer factors. Four days later the chicks were killed and their caecal contents examined for the presence of $\mathrm{R}+S$. typhimurium. Two methods were used,

Received 12 Jan. 1972; accepted 26 Jan. 1972.

J. MED. MICROBIOL.-VOL. 5 (1972) 
the object being to obtain as many strains as possible that possessed different $\mathbf{R}$ factors. In the first method, the caecal contents were smeared over the surface of MacConkey's agar, Brilliant Green Agar (Oxoid, CM263), Bismuth Sulphite Agar (Oxoid, CM201) or Desoxycholate-Citrate-Agar (Oxoid, CM227) in petri dishes, and disks containing different antibiotics were applied. In the second, the caecal contents were inoculated in a manner likely to yield well-separated colonies on to plates of the same four media this time containing one or more antibiotics. Sodium nalidixate was added to all the media used for isolating $\mathrm{R}+$ forms of the nal ${ }^{\mathrm{r}}$ mutant strains of $S$. typhimurium irrespective of whether other antibiotics were also added. The plates were incubated at $37^{\circ} \mathrm{C}$ for $24-48 \mathrm{hr}$ and examined for the presence of antibioticresistant salmonella colonies. One or more were removed, purified by replating and their antibiotic-sensitivity pattern determined by the Multodisk method (Smith, 1970). They were kept on Dorset egg medium at $4^{\circ} \mathrm{C}$ until needed; those derived from $\mathrm{nal}^{\mathrm{r}}$ mutants were given the prefix nalr. The $\mathrm{R}+S$. typhimurium organisms that grew on some of the plates of antibiotic-containing MacConkey's medium outnumbered the $E$. coli that also grew on them, providing additional evidence that transfer in this type of experiment occurs in the alimentary tract and not on the culture medium (Smith, 1970).

The $\mathrm{R}^{-}$parent strains were re-isolated from some of the plates inoculated with caecal contents for subsequent use in the virulence tests; none was found to have acquired transfer factors during its sojourn in the alimentary tract.

Smooth S. typhimurium strains. Strains were classed as smooth if (1) they possessed the typical colonial morphology associated with smoothness, (2) they produced an even turbidity in nutrient broth culture, (3) they were agglutinated by $S$. typhimurium 0 antiserum in slide tests, but not by $0 \cdot 2$ per cent. acriflavine solution and (4) they were lysed by the $0-1$ phage (Felix and Callow, 1943) in plate tests, but not by phage 6SR (Kay, 1962). All the $\mathrm{R}^{+}$ strains of $S$. typhimurium isolated from caecal contents and subsequently used in virulence tests satisfied these criteria.

Removal of $R$ factors from $S$. typhimurium. Acridine orange, according to the method of Hirota (1960), and ethidium bromide, according to the method of Bouanchaud, Scavizzi and Chabbert (1968), were employed in attempts to eliminate R factors from $S$. typhimurium. The strains from which they were removed were then examined to determine whether or not they still possessed transfer factors.

The detection of transfer factors in $R^{-}$strains of $S$. typhimurium. This was achieved by means of antibiotic resistance determinant-mobilisation tests (Anderson, 1965) according to

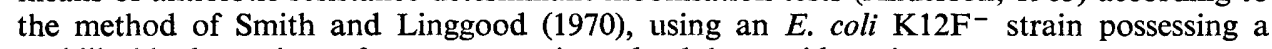
mobilisable determinant for streptomycin and sulphonamide resistance.

Virulence tests. Male Arbor Acre sex-linked chicks in their 1st day of life, and before they were provided with food and water, were given $0.5 \mathrm{ml}$ of a broth culture of $S$. typhimurium that had been agitated continuously during incubation at $37^{\circ} \mathrm{C}$ for $24 \mathrm{hr}$. This represented a dose of $7.5 \times 10^{8}$ viable organisms; it was placed directly in the crop by means of a Pasteur pipette passed down the oesophagus.

The chicks were kept in groups of 50 on littered floors in identically constructed solidsided pens in an animal house kept at $21^{\circ} \mathrm{C}$. Additional heating was provided by suspending an infra-red brooding lamp over each pen. The birds were fed ad libitum on a diet of the following composition: wheat meal, 40 per cent.; maize meal, 40 per cent.; British white fish meal, 20 per cent.; mineral and vitamin supplement, $0 \cdot 25$ per cent.

Occasional consignments of chicks varied in their susceptibility to fatal infection. Because of this, each complete experiment was performed on the same consignment of birds. This permitted 50 chicks to be used in each group in each experiment. When larger groups were necessary the entire experiment was replicated in further consignments.

The antibiotic-resistance pattern of the $S$. typhimurium organisms in the liver and yolk sac of a representative sample of the chicks that died in each group was determined. Loss of $R$ determinants occurred comparatively infrequently; it will be mentioned when it might have been of some significance. The experiments were terminated 14 days after their commencement because after that time deaths were uncommon. The total mortality rates were analysed statistically by Dr P. K. Pani. 


\section{RESULTS}

The mortality rate in chicks infected with different $R^{+}$strains of Salmonella typhimurium no. 5235

The results of infecting orally groups of 2001 -day-old chicks with strains of Salmonella typhimurium no. 5235 (phage type 29), or of nalidixic acidresistant ( nal $^{\mathrm{r}}$ ) mutants of this strain, that had acquired different $\mathrm{R}$ factors

TABLE I

Mortality rate amongst groups of 200 chicks infected with different $R^{-}$and $R^{+}$ strains of Salmonella typhimurium no. 5235 (phage-type 29)

\begin{tabular}{|c|c|c|c|c|c|c|c|c|c|c|c|c|c|c|c|}
\hline \multirow{2}{*}{$\begin{array}{c}\text { Strain } \\
\text { number }\end{array}$} & \multirow{2}{*}{$\begin{array}{c}\text { Transmissible } \\
\text { resistance } \\
\text { pattern* }\end{array}$} & \multicolumn{14}{|c|}{ Percentage dead at the following days after infection } \\
\hline & & 1 & 2 & 3 & 4 & 5 & 6 & 7 & 8 & 9 & 10 & 11 & 12 & 13 & 14 \\
\hline $\begin{array}{l}9 \\
1 \\
5 \\
2 \\
3 \\
6 \\
7 \\
8\end{array}$ & $\begin{array}{l}\text { None } \\
\text { None } \\
\text { T } \\
\text { AT } \\
\text { ASSuTC } \\
\text { ASN } \\
\text { ASSuCN } \\
\text { ASSuTCN }\end{array}$ & $\begin{array}{l}1 \\
0 \\
2 \\
2 \\
1 \\
1 \\
1 \\
1\end{array}$ & $\begin{array}{l}8 \\
9 \\
7 \\
8 \\
9 \\
2 \\
5 \\
3\end{array}$ & $\begin{array}{r}20 \\
14 \\
14 \\
15 \\
14 \\
9 \\
8 \\
8\end{array}$ & $\begin{array}{l}30 \\
22 \\
19 \\
21 \\
19 \\
15 \\
13 \\
11\end{array}$ & $\begin{array}{l}34 \\
25 \\
23 \\
24 \\
21 \\
19 \\
14 \\
13\end{array}$ & $\begin{array}{l}36 \\
28 \\
29 \\
28 \\
28 \\
21 \\
17 \\
16\end{array}$ & $\begin{array}{l}38 \\
30 \\
33 \\
31 \\
29 \\
23 \\
19 \\
19\end{array}$ & $\begin{array}{l}42 \\
34 \\
34 \\
33 \\
31 \\
27 \\
19 \\
20\end{array}$ & $\begin{array}{l}44 \\
37 \\
36 \\
36 \\
33 \\
29 \\
21 \\
21\end{array}$ & $\begin{array}{l}46 \\
39 \\
38 \\
37 \\
35 \\
31 \\
22 \\
21\end{array}$ & $\begin{array}{l}48 \\
40 \\
39 \\
39 \\
37 \\
34 \\
23 \\
23\end{array}$ & $\begin{array}{l}50 \\
42 \\
40 \\
39 \\
38 \\
35 \\
26 \\
24\end{array}$ & $\begin{array}{l}50 \\
42 \\
40 \\
40 \\
38 \\
36 \\
27 \\
24\end{array}$ & $\begin{array}{l}50 \\
42 \\
41 \\
41 \\
39 \\
37 \\
27 \\
24\end{array}$ \\
\hline $\begin{array}{l}\text { nal }^{\mathbf{r}} 1 \dagger \\
\text { nal }^{\mathbf{r}} 4 \\
\text { nal }^{\mathbf{r}} 2 \\
\text { nal }^{\mathbf{r}} 3\end{array}$ & $\begin{array}{l}\text { None } \\
\text { T } \\
\text { ASN } \\
\text { SSuTC }\end{array}$ & $\begin{array}{l}1 \\
1 \\
3 \\
1\end{array}$ & $\begin{array}{l}8 \\
6 \\
8 \\
3\end{array}$ & $\begin{array}{r}16 \\
11 \\
12 \\
7\end{array}$ & $\begin{array}{l}24 \\
19 \\
21 \\
12\end{array}$ & $\begin{array}{l}31 \\
25 \\
24 \\
15\end{array}$ & $\begin{array}{l}33 \\
28 \\
26 \\
16\end{array}$ & $\begin{array}{l}36 \\
30 \\
27 \\
18\end{array}$ & $\begin{array}{l}39 \\
33 \\
28 \\
22\end{array}$ & $\begin{array}{l}43 \\
36 \\
31 \\
24\end{array}$ & $\begin{array}{l}44 \\
38 \\
33 \\
25\end{array}$ & $\begin{array}{l}45 \\
38 \\
34 \\
27\end{array}$ & $\begin{array}{l}48 \\
39 \\
36 \\
28\end{array}$ & $\begin{array}{l}49 \\
40 \\
36 \\
28\end{array}$ & $\begin{array}{l}49 \\
41 \\
37 \\
28\end{array}$ \\
\hline
\end{tabular}

* $\mathrm{A}=$ Ampicillin, $\mathrm{S}=$ streptomycin, $\mathrm{Su}=$ sulphonamide, $\mathrm{T}=$ tetracyline, $\mathrm{C}=$ chloramphenicol and $\mathbf{N}=$ neomycin.

$\dagger$ nal $^{\mathrm{r}}=$ Nalidixic acid-resistant mutant.

Each chick was given $7.5 \times 10^{8}$ viable organisms of $S$. typhimurium strain 5235 during its 1 st day of life.

$\left(\mathrm{R}^{+}\right)$in vivo are summarised in table $\mathrm{I}$. The results for two of the nalidixic acid-sensitive $\left(n a l^{\mathrm{s}}\right)$ and for one $n a l^{\mathrm{r}}$ mutant strain that had not acquired $\mathrm{R}$ factors $\left(\mathrm{R}^{-}\right)$in vivo are included for comparison.

$\mathrm{Nal}^{s}$ strains. The total mortality rate produced by two of the six $\mathrm{R}+$ strains tested (nos. 7 and 8 ) was significantly lower than the average of those produced by the two $\mathrm{R}-$ strains 9 and $1(\mathrm{P}<0 \cdot 01)$.

Nalr strains. The total mortality rate produced by two of the three $\mathrm{R}^{+}$ strains (nos. nal 2 and 3) was significantly lower than that produced by the $R$ - strain, nal $1(\mathrm{P}<0 \cdot 01)$.

The mortality rate in chicks infected with different $R+$ strains of S. typhimurium no. 98

The results of infecting orally groups of 100 1-day-old chicks with nal $^{\mathrm{s}}$ and nal $^{\mathrm{r}}$ strains of $S$. typhimurium no. 98 (phage type 14) that had acquired $\mathrm{R}$ factors in vivo are summarised in table II. 
Nals strains. The total mortality rates produced by all except two of the $11 \mathrm{R}+$ strains (nos. 39 and 33) was significantly lower than the average of those produced by the $R^{-}$strains $(P<0.01)$. Two of the $R+$ strains (nos. 3 and 46 ) possessed the same antibiotic resistance pattern but produced quite different

TABLE II

Mortality rate amongst groups of 100 chicks infected with different $R^{-}$and $R^{+}$ strains of Salmonella typhimurium no. 98 (phage-type 14)

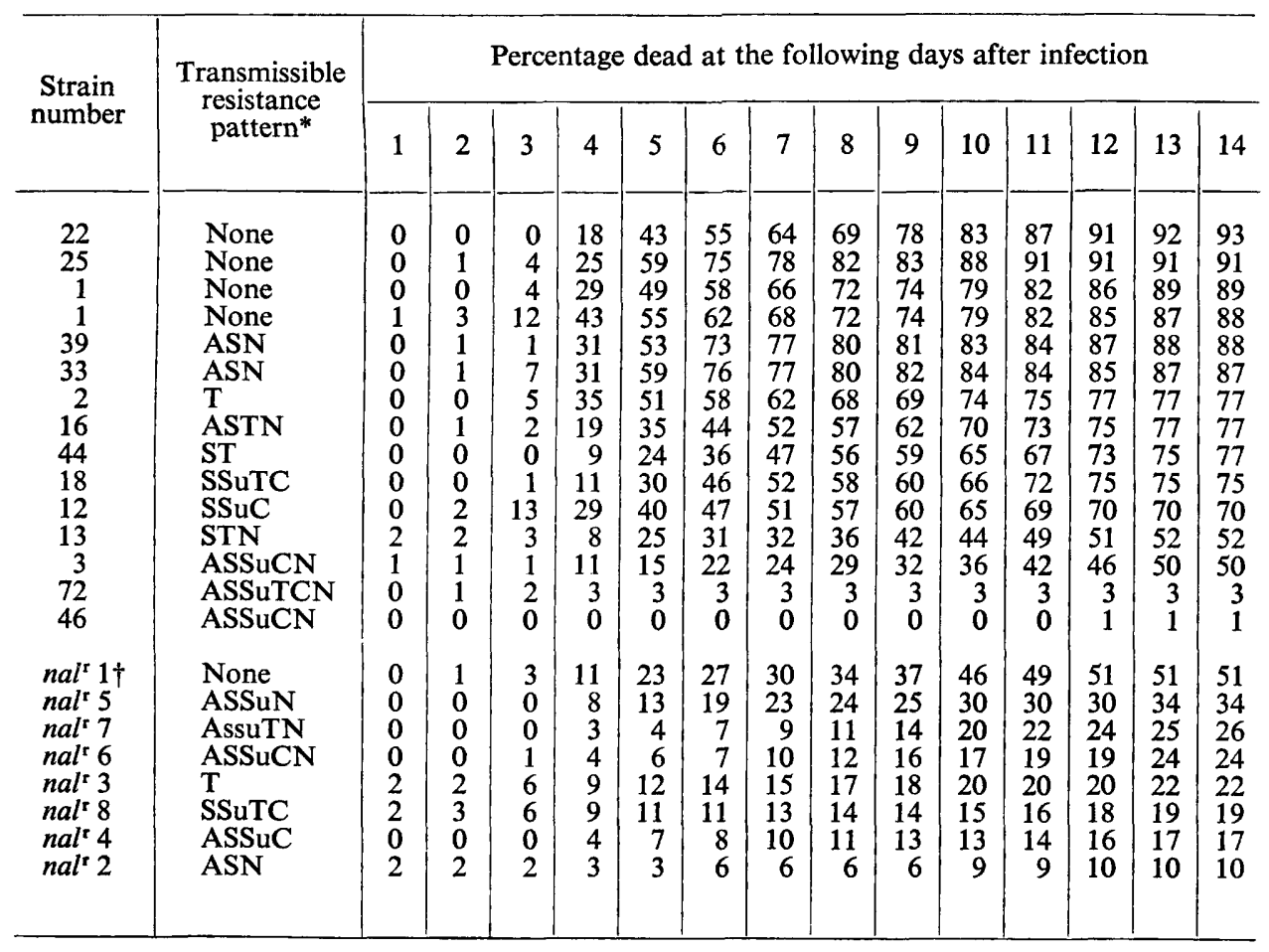

* $\mathrm{A}=$ Ampicillin, $\mathrm{S}=$ streptomycin, $\mathrm{Su}=$ sulphonamide, $\mathrm{T}=$ tetracycline, $\mathrm{C}=$ chloramphenicol and $\mathrm{N}=$ neomycin.

$\dagger$ nal ${ }^{r}=$ Nalidixic acid-resistant mutant.

Each chick was given $7 \cdot 5 \times 10^{8}$ viable organisms of $S$. typhimurium strain 98 during its 1 st day of life.

mortality rates. That produced by nos. 46 and 72 was very much lower than that produced by the other seven strains. The $\mathrm{R}$ factors in both these strains were unstable. For example, only one of the six isolates of $S$. typhimurium obtained from six survivors of the chicken infected with strain 46 still possessed the complete set of determinants; the other five were resistant to ampicillin, streptomycin and neomycin only.

Nalr strains. Unlike the position in strain 5235 , the nal $^{\mathrm{r}}$ variant of strain 98 was less virulent than the $n a l^{\mathbf{s}}$ strain from which it was prepared. All seven $\mathrm{R}+n a l^{\mathrm{r}}$ strains tested were less virulent than the $\mathrm{R}-\operatorname{strain}(\mathrm{P}<0 \cdot 01)$. 
The effect on virulence of removing resistance determinants and transfer factors from $R^{+}$strains of S. typhimurium no. 98

The results of infecting groups of 200 1-day-old chicks with $\mathrm{R}+$ strains of S. typhimurium no. 98 or with the same strains after their resistance determinants had been eliminated ( $\mathrm{RD}-\mathrm{TF}^{+}$) and, in the case of one strain (no. 51), their transfer factors also ( $\mathrm{RD}^{-} \mathrm{TF}^{-}$) is summarised in table III. These were the

\section{TABLE III}

Mortality rate amongst groups of 200 chicks infected with strains of Salmonella typhimurium no. 98 whose resistance determinants and transfer factors had or had not been eliminated

\begin{tabular}{c|l|l|r|r|r|r|r|r|r|r|r|r|r|r|r|r}
\hline \multicolumn{3}{c|}{ Infecting strain } & \multicolumn{8}{c}{ Percentage dead at the following days after infection } \\
\hline Number & $\begin{array}{c}\text { Resistance } \\
\text { determinants* }\end{array}$ & $\begin{array}{c}\text { Transfer } \\
\text { factors }\end{array}$ & 1 & 2 & 3 & 4 & 5 & 6 & 7 & 8 & 9 & 10 & 11 & 12 & 13 & 14 \\
\hline $1 \dagger$ & None & Absent & 1 & 1 & 3 & 9 & 21 & 31 & 40 & 45 & 50 & 52 & 55 & 57 & 59 & 61 \\
13 & STN & Present & 0 & 1 & 1 & 3 & 10 & 17 & 20 & 23 & 26 & 28 & 30 & 30 & 31 & 31 \\
13 & Eliminated & Present & 1 & 1 & 2 & 5 & 10 & 15 & 18 & 21 & 23 & 25 & 27 & 29 & 30 & 30 \\
12 & SSuC & Present & 1 & 2 & 2 & 4 & 7 & 9 & 15 & 21 & 25 & 30 & 32 & 34 & 35 & 36 \\
12 & Eliminated & Present & 0 & 1 & 1 & 5 & 13 & 21 & 25 & 31 & 33 & 35 & 40 & 44 & 44 & 46 \\
51 & SSuC & Present & 1 & 1 & 2 & 3 & 3 & 5 & 7 & 11 & 12 & 15 & 18 & 20 & 20 & 20 \\
51 & Eliminated \\
51 & Eliminated & Eresent & 1 & 1 & 1 & 1 & 3 & 7 & 8 & 10 & 14 & 14 & 15 & 16 & 22 & 23 \\
& Eliminated & 1 & 1 & 3 & 6 & 20 & 32 & 39 & 46 & 48 & 52 & 57 & 59 & 62 & 63 \\
\hline
\end{tabular}

* $\mathrm{S}=$ Streptomycin, $\mathrm{Su}=$ sulphonamide, $\mathrm{T}=$ tetracycline, $\mathrm{C}=$ chloramphenicol and $\mathrm{N}=$ neomycin.

$\dagger$ Strain 1 could not be shown to possess an $\mathrm{R}$ determinant or a transfer factor.

Each chick was given $7.5 \times 10^{8}$ viable organisms of one or other of the different strains of S. typhimurium no. 98 during its 1 st day of life.

only $\mathbf{R}+$ strains of several examined from which all the resistance determinants could be eliminated. The results for strain 1 , the $\mathrm{RD}-\mathrm{TF}-$ strain from which these $\mathrm{R}^{+}$strains were originally prepared in vivo is included for comparison. There was no difference between the total mortality rates produced by the $\mathrm{RD}+\mathrm{TF}+$ and $\mathrm{RD}-\mathrm{TF}+$ forms of strain $13(\mathrm{P}>0.05)$ but that produced by the $\mathrm{RD}-\mathrm{TF}+$ form of strain 12 was slightly but significantly higher than that produced by the $\mathrm{RD}+\mathrm{TF}+$ form $(\mathrm{P}<0.05)$. There was no significant difference between the results for the corresponding two forms of strain $51\left(\mathrm{P}_{>} 0.05\right)$. The $\mathrm{RD}-\mathrm{TF}$ - form of this strain, however, produced a much higher mortality rate than the other two forms $(\mathrm{P}<0.01)$, a rate that did not differ significantly from that produced by strain 1 itself $(P>0.05)$.

The virulence of a further seven $\mathrm{RD}-\mathrm{TF}$ - and two RD - TF + strains, obtained from strain 51 by acridine orange or ethidium bromide treatment, was assessed in groups of 50 chicks. The results were similar to those illustrated in table III. The total percentage mortality rates in the seven groups given the $\mathrm{RD}-\mathrm{TF}$ - strains was $70,68,66,60,58,50$ and 50 and in the two groups given 
the $\mathrm{RD}-\mathrm{TF}+$ strains was 34 and 34 . The corresponding figure for the group given the $\mathrm{RD}+\mathrm{TF}+$ strain 51 was 26 and for the group given the RD-TF strain 1 was 60 .

The virulence of $S$. typhimurium no. 98 , strain 1 , that had received $R$ factors in vitro at a high rate from strains 12,51 and 46

The mortality rate in groups of chicks given S. typhimurium no. 98 strains 1, 12,51 or 46 , or strain 1 after it had received the R factors of strains 12,51 or 46 in vitro, are illustrated in table IV. The R factors were first transferred from the three donor strains to $E$. coli $\mathrm{K} 12 \mathrm{~F}^{-}$and from this strain to strain 1 . In the final transfer in each case approximately 25 per cent. of the prospective recipient organisms had acquired the $\mathbf{R}$ factors of the donor strains; this

TABLE IV

The mortality rate amongst groups of 300 chicks infected with strains of Salmonella typhimurium no. 98 that had received $R$ factors in vivo or in vitro

\begin{tabular}{|c|c|c|c|c|c|c|c|c|c|c|c|c|c|c|c|}
\hline \multicolumn{2}{|c|}{ Infecting strain } & \multicolumn{14}{|c|}{ Percentage dead at the following days after infection } \\
\hline Number & $\begin{array}{l}\mathrm{R} \text { factor } \\
\text { present* }\end{array}$ & 1 & 2 & 3 & 4 & 5 & 6 & 7 & 8 & 9 & 10 & 11 & 12 & 13 & 14 \\
\hline 1 & None & $\mathbf{0}$ & 1 & 1 & 8 & 24 & 36 & 43 & 49 & 52 & 56 & 60 & 62 & 64 & 64 \\
\hline$\frac{12}{1(12) \dagger}$ & $\begin{array}{l}\text { SSuC } \\
\text { SSuC }\end{array}$ & $\begin{array}{l}0 \\
0\end{array}$ & $\begin{array}{l}0 \\
1\end{array}$ & $\begin{array}{l}2 \\
1\end{array}$ & $\begin{array}{l}3 \\
6\end{array}$ & $\begin{array}{r}8 \\
17\end{array}$ & $\begin{array}{l}13 \\
23\end{array}$ & $\begin{array}{l}18 \\
28\end{array}$ & $\begin{array}{l}25 \\
33\end{array}$ & $\begin{array}{l}28 \\
36\end{array}$ & $\begin{array}{l}34 \\
40\end{array}$ & $\begin{array}{l}36 \\
43\end{array}$ & $\begin{array}{l}38 \\
46\end{array}$ & $\begin{array}{l}39 \\
47\end{array}$ & $\begin{array}{l}40 \\
47\end{array}$ \\
\hline $\begin{array}{l}51 \\
1(51)\end{array}$ & $\underset{\text { SSuC }}{\text { SSuC }}$ & $\begin{array}{l}0 \\
0\end{array}$ & $\begin{array}{l}0 \\
0\end{array}$ & $\begin{array}{l}0 \\
1\end{array}$ & $\begin{array}{l}1 \\
3\end{array}$ & $\begin{array}{l}5 \\
8\end{array}$ & $\begin{array}{r}8 \\
12\end{array}$ & $\begin{array}{l}11 \\
15\end{array}$ & $\begin{array}{l}16 \\
19\end{array}$ & $\begin{array}{l}18 \\
22\end{array}$ & $\begin{array}{l}20 \\
27\end{array}$ & $\begin{array}{l}23 \\
30\end{array}$ & $\begin{array}{l}25 \\
33\end{array}$ & $\begin{array}{l}26 \\
34\end{array}$ & $\begin{array}{l}27 \\
35\end{array}$ \\
\hline $\begin{array}{l}46 \\
1(46)\end{array}$ & $\begin{array}{l}\text { ASSuCN } \\
\text { ASSuCN }\end{array}$ & $\begin{array}{l}0 \\
0\end{array}$ & $\begin{array}{l}1 \\
1\end{array}$ & $\begin{array}{l}1 \\
1\end{array}$ & $\begin{array}{l}1 \\
6\end{array}$ & $\begin{array}{r}1 \\
12\end{array}$ & $\begin{array}{r}1 \\
22\end{array}$ & 31 & $\begin{array}{r}1 \\
39\end{array}$ & $\begin{array}{r}1 \\
42\end{array}$ & $\begin{array}{r}2 \\
44\end{array}$ & $\begin{array}{r}2 \\
48\end{array}$ & $\begin{array}{r}2 \\
53\end{array}$ & $\begin{array}{r}2 \\
54\end{array}$ & $\begin{array}{r}2 \\
55\end{array}$ \\
\hline
\end{tabular}

\footnotetext{
* $\mathrm{A}=$ Ampicillin, $\mathrm{S}=$ streptomycin, $\mathrm{Su}=$ sulphonamide, $\mathrm{C}=$ chloramphenicol and $\mathbf{N}=$ neomycin.

$\dagger$ The numbers in brackets are those of the strains whose $\mathrm{R}$ factors, received initially in vivo, had now been transmitted in vitro to strain 1 .

Each chick was given $7.5 \times 10^{8}$ viable organisms of one or other of the different strains of $S$. typhimurium no. 98 during its 1 st day of life.
}

transfer rate was considered sufficiently high to negate the possibility of the transfer process acting as a selection mechanism for recipient organisms of reduced virulence. The mortality rates produced by the two forms of strain 1 that had received $\mathrm{R}$ factors from strain 12 or from strain 51, i.e., 1(12) and $1(51)$, were significantly lower than that produced by strain 1 itself $(P<0 \cdot 01)$. That produced by strain 1(12) was not significantly different from that produced by strain $12(P>0.05)$ whereas that produced by strain $1(51)$ was only slightly higher than that produced by strain $51(\mathrm{P}<0.05)$, i.e., the virulence of the resistant strains produced in vitro resembled that produced in vivo. The mortality rate produced by the form of strain 1 that had received $R$ factors from strain 
46 , i.e., $1(46)$, was significantly lower than that produced by strain $1(P<0.01)$ but it was still very much higher than that produced by strain 46 itself.

\section{Discussion}

When Salmonella typhimurium was able to acquire $\mathrm{R}$ factors from $\mathrm{R}^{+}$ Escherichia coli in the alimentary tract, the virulence of organisms that acquired them was generally similar to, rather less than, or much less than the virulence of those that did not. The virulence tests on S. typhimurium strains whose transfer factors and resistance determinants had been eliminated (table III) and on strains that had acquired $\mathrm{R}$ factors at a high rate in vitro (table IV) suggest that it is the very possession of resistance determinants and, probably to a greater extent, of transfer factors that may be responsible for the reduced virulence of some $\mathrm{R}^{+}$strains of $S$. typhimurium; this view is supported by the observation (table III) that the removal of these genetic elements by acridine orange sometimes restored their virulence to that of the parent strain. Whereas the presence of these elements appeared to be responsible for some of the decreased virulence exhibited by strain 46 (table IV) it was not responsible for the major part. This strain and strain 72 (table II)-a strain of similar virulence -may have been less virulent variants of the $\mathrm{R}$ - parent strain of S. typhimurium no. 98 that had subsequently acquired $\mathrm{R}$ factors in our in vivo transfer experiments.

The S. typhimurium strains whose virulence was compared in the present study, were specially selected so that most of them contained different $\mathbf{R}$ factors. Consequently, the results obtained do not give a quantitative assessment of the alteration in virulence that might be expected to follow the acquisition of $\mathrm{R}$ factors by $S$. typhimurium populations in the alimentary tract. For example, during the assembly of the collection, by far the most common $\mathrm{R}^{+}$ strains of $S$. typhimurium found in the caecal contents of the chicks that had been given an $\mathrm{R}^{-}$strain of this organism and $\mathrm{R}^{+}$strains of $E$. coli were those that were resistant to tetracyclines, to ampicillin, streptomycin and neomycin, and to streptomycin, sulphonamide and chloramphenicol. The virulence of these strains was either similar to or rather lower than that of the corresponding $\mathrm{R}$ - strain. In contrast, the two strains in the collection of least virulence, strains 46 and 72 , possessed $\mathrm{R}$ factors that were found much less commonly amongst the $\mathrm{R}+S$. typhimurium isolated from the caecal contents. These facts should be borne in mind when attempting to assess the significance of the acquisition of $\mathrm{R}$ factors by pathogenic organisms under natural conditions.

\section{SUMMARY}

Different $\mathrm{R}$ factors were transferred from $\mathrm{R}+$ Escherichia coli to two strains of Salmonella typhimurium in the alimentary tract of chicks. The virulence of the $\mathrm{R}+S$. typhimurium strains was then compared with the $\mathrm{R}-$ strains from which they were derived by giving them orally to groups of 1-day-old chicks.

The mortality rates from infection with the $R+$ strains were similar to, slightly lower than, or much lower than those from infection with the corresponding $\mathbf{R}$ - strains. 
Virulence tests on $S$. typhimurium strains from which $\mathrm{R}$ factors had been eliminated, and on strains to which $\mathbf{R}$ factors had been transferred at a high rate in vitro, suggested that the very possession of $\mathrm{R}$ factors was responsible for the smaller reductions in mortality rate observed with some of the $\mathrm{R}+$ strains; but the other strains with which greatly reduced mortality rates were observed may have been low-virulence variants of the $R$ - parent strain that had subsequently acquired $\mathrm{R}$ factors from the $\mathrm{R}+E$. coli.

I am grateful to Miss Diane Poulton, Miss Carole Smith and Miss Marion White for their capable technical help. My thanks are also due to Mr L. J. Abbott, Dr E. S. Anderson, Mrs Anne Millington and Dr P. K. Pani for assistance in various ways. All the chicks used in this work were a gift from Arbor Acres (U.K.) Ltd.

\section{REFERENCES}

ANDERSON, E. S. 1965. A rapid screening test for transfer factors in drug-sensitive Enterobacteriaceae. Nature, Lond., 208, 1016.

Bouanchaud, D. H., Scavizzi, M. R., AND Chabbert, Y. A. 1968. Elimination by ethidium bromide of antibiotic resistance in enterobacteria and staphylococci. J. Gen. Microbiol., $54,417$.

Felix, A., and Callow, Bessie R. 1943. Typing of paratyphoid B bacilli by means of Vi bacteriophage. Br. Med. J., 2, 127.

HiRota, Y. 1960. The effect of acridine dyes on mating type factors in Escherichia coli. Proc. Natn. Acad. Sci., USA, 46, 57.

KAY, D. 1962. The nucleic acid composition of bacteriophage $\theta$ R. J. Gen. Microbiol., 27, 201.

SмIтн, H. W. 1970. The transfer of antibiotic resistance between strains of enterobacteria in chickens, calves and pigs. J. Med. Microbiol., 3, 165 .

SMIth, H. W., AND LingGoOd, Margaret A. 1970. Transfer factors in Escherichia coli with particular regard to their incidence in enteropathogenic strains. J. Gen. Microbiol., 62, 287.

ThIELE, Elizabeth H. 1970. Virulence of R-factor-bearing Salmonella typhimurium. Infect. Immun., 2, 516.

WATANABE, T. 1971. Transferable antibiotic resistance in enterobacteriaceae: relationship to the problems of treatment and control of coliform enteritis. Ann. N.Y. Acad. Sci., 176, 371.

WATANABE, T., AND WATANABE, M. 1969. Episomic resistance factors in Enterobacteriaceae: 38. Virulence for mice of Salmonella typhimurium LT-2 carrying various R factors. Igaku to Seibutsugaku, 79, 139 (in Japanese). 